\title{
Comparative Evaluation of Nemoceph and Foxit PDF Reader for Steiner's Cephalometric Analysis
}

\author{
Mukesh Kumar ${ }^{1}$, Sommya Kumari ${ }^{2}$, Pramod Shetty ${ }^{3}$, Reena Ranjeet Kumar ${ }^{4}$, Dhirendra Pratap Singh ${ }^{5}$, Prakrathi Shetty ${ }^{6}$
}

\begin{abstract}
Aim: The aim of this study was to evaluate and compare the values of Steiner's cephalometric analysis using Nemoceph and Foxit PDF Reader. No significant difference between the two methods will result in that Foxit PDF Reader can be used as a cost-effective alternative.

Materials and methods: This study was conducted on 100 digital lateral cephalograms taken from the same machine. The samples were collected by nonprobability convenience sampling procedures. These images were analyzed for Steiner's cephalometric analysis using two software packages.

Results: The skeletal and dental values showed no statistically significant difference in the majority, except for the L1-NA (linear) and L1-NB (linear). Conclusion: Results showed that there is a high agreement between the two methods.

Clinical significance: This article provides a simple and cost-effective method of onscreen cephalometric analysis. This technique uses the inbuilt measurement tools in the tool bar of our daily use software. The method can be used independently anywhere without any internet connection and software subscription.

Keywords: Cephalometry, Digital imaging, Onscreen tracing.

The Journal of Contemporary Dental Practice (2019): 10.5005/jp-journals-10024-2645
\end{abstract}

\section{INTRODUCTION}

Harmonious facial esthetics and optimal functional occlusion with a firm structural balance is a recognized canon for orthodontists. ${ }^{1,2}$ A scientific approach to analyze the human craniofacial patterns was pioneered by anthropologists and anatomists. ${ }^{3-5}$ Since the introduction of cephalometric radiography by Broadbent in 1931, significant advancement has been achieved over the years., ${ }^{4,6} 7$ The vital role of cephalometric analysis in orthodontic diagnosis, treatment planning, and monitoring treatment and growth changes is well established. . $^{7}$

The traditional hand-tracing process of cephalometric analysis uses an acetate overlays, pencil, ruler, and protractor to measure the linear and angular values. Though most economical and accessible, the potential systematic and random error, high time demand, special dark chamber, chemical hazard, together with difficult archiving are among the possible cause of its set back. ${ }^{10,11}$

Digital radiographic technique emerged during the late 1980s and early 1990 s brought the cephalometric radiographs on screen. These digital cephalometric images created a surge for computer cephalometric analysis software. ${ }^{12}$ Many cephalometric analysis programs were developed since then claiming themselves "better than the best." This technological advancement not only overcome the limitations of the manual cephalometric technique but also enabled brightness and contrast control facility for easy landmark identification, leading to accuracy. ${ }^{13-16}$

The availability, affordability, and user-friendly score of this commercially available software remained questionable. ${ }^{17}$ Therefore, the present study was conducted with an objective to compare the mean values obtained by evaluating digital lateral cephalograms using Nemoceph cephalometric analysis software (Nemoceph NX 2009 for Windows) and the general measurement tools available in the toolbar of Foxit PDF Reader (Foxit PDF Reader, version 3.0) for Steiner's cephalometric analysis.
${ }^{1}$ Department of Orthodontics, Pacific Academy of Higher Education and Research, Udaipur, Rajasthan, India

${ }^{2}$ Department of Prosthodontics, Buddha Institute of Dental Sciences and Hospital, Patna, Bihar, India

${ }^{3,6}$ Department of Orthodontics, Pacific Dental College, Udaipur, Rajasthan, India

${ }^{4}$ D J College of Dental Sciences and Research, Modinagar, Uttar Pradesh, India

${ }^{5}$ Department of Orthodontics, Chandra Dental College and Hospital, Barabanki, Uttar Pradesh, India

Corresponding Author: Sommya Kumari, Department of Prosthodontics, Buddha Institute of Dental Sciences and Hospital, Patna, Bihar, India, Phone: +91 8969859326, e-mail: sommyakumari@ gmail.com

How to cite this article: Kumar M, Kumari $S$, et al. Comparative Evaluation of Nemoceph and Foxit PDF Reader for Steiner's Cephalometric Analysis. J Contemp Dent Pract 2019;20(9):1051-1055.

Source of support: Nil

Conflict of interest: None

\section{Materials and Methods}

The study was conducted in the Department of Orthodontics and Dentofacial Orthopedics at Pacific Dental College, Udaipur, Rajasthan. One hundred digital lateral cephalograms of the prospective orthodontic patients reporting to the OPD of the Orthodontic Department were included in the study. The study was approved by the institutional research committee and is recognized by the scholar's enrollment number. Since this study used diagnostic images of prospective orthodontic patients, and no subject was radiated without an indication. Therefore, specific ethical committee 
clearance was not required. This study compared the mean values of the samples studied, and no patient-specific data was disclosed. Therefore, informed consent of the patient was not necessary.

All the radiographs were taken from the same digital OPG machine with an automatic $\mathrm{KVp}$ and $\mathrm{mA}$ setting. All the radiographs were taken by the same radiographic technician, adhering to the radiation hygiene protocol. The samples were selected through nonprobability convenience sampling procedures. All the radiographs were selected based on the quality and clarity of images and with ease for identification of landmarks. The selection criteria were not to be affected by age, gender, machine, head positioning, and tooth contact. Poor quality image, distortion, artifact, and craniofacial anomalies were excluded from the study. Angle's system of classification did not affect the selection criteria.

A laptop with a mouse-controlled cursor was used for onscreen landmark identification and cephalometric analysis. The following landmarks were identified: sella, nasion, point- $A$, point- $B$, gnathion, gonion, upper incisor incisal edge, upper incisor root apex, lower incisor incisal edge, lower incisor root apex, upper first molar cusp tip, and lower first molar cusp tip. The landmark identification was done for all the radiographs using both the software:

- Nemoceph NX 2009 for Windows (commercially available) and - Foxit PDF Reader, version 3.0 (free download software)

Image magnification and contrast enhancement tools were used for easy identification of landmarks in both the software evaluated. All the cephalograms were evaluated by the same operator using both the software. Only 05 (five) cephalograms were evaluated using either of the software in each session to minimize error. The interval between the sessions was maintained to be 24 hours to prevent operator fatigue.

The lateral cephalometric radiographs were cropped to the size of standard lateral head film ( $8 \times 10$ inches) using Adobe Photoshop. A ruler scale image of 8 inches was added on the top of this image, extending from the right margin to the left margin for easy calibration with the software to be tested. The standardized and calibrated images were numbered $1-100$ on the upper righthand side corner of the images for identification. The images were saved in JPEG and PDF format, with a maximum quality setting at 200 dpi, for evaluation with Nemoceph and Foxit PDF Reader software, respectively.

The cephalometric images (in JPEG format) were first evaluated using Nemoceph NX 2009 software for Windows (Nemotec, Madrid, and Spain). The landmarks were marked as per the software demand and as shown in the lower right corner of the screen. After the completion of landmark identification, the tracing was contoured to the best match with the radiographic image. Further, the cephalometric values for Steiner's analysis were taken from the dropbox of the software (Fig. 1).

The cephalometric images (in PDF format) were then opened using Foxit PDF Reader and "Tool Box" on the top margin was used for all the purposes. The reference planes were drawn using the "Line Tool" and adjusted using the mouse cursor if required. Further, the "Distance Tool" and the "Area Tool" were used for the linear and the angular measurements, respectively. Immediately the observed values were recorded manually on a paper, as this software is not customized for any specific purpose, and therefore there is no provision of consolidated data collection (Fig. 2).

The data were subjected to statistical analyses using Statistical Package for Social Sciences Software version 11.0 (SPSS Inc., Chicago, IL). One-way ANOVA was used for comparison between

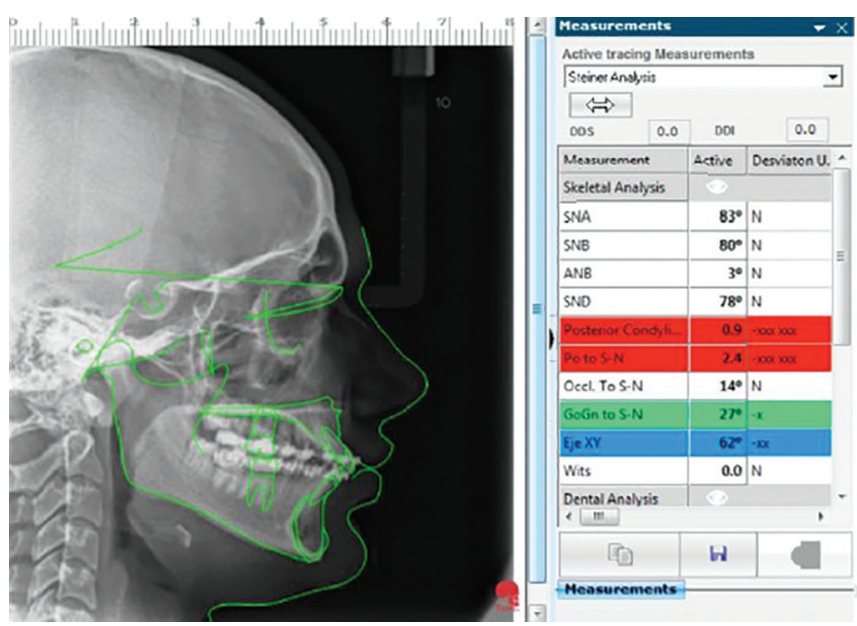

Fig. 1: Cephalometric analysis measurement using Nemoceph software with measurement values

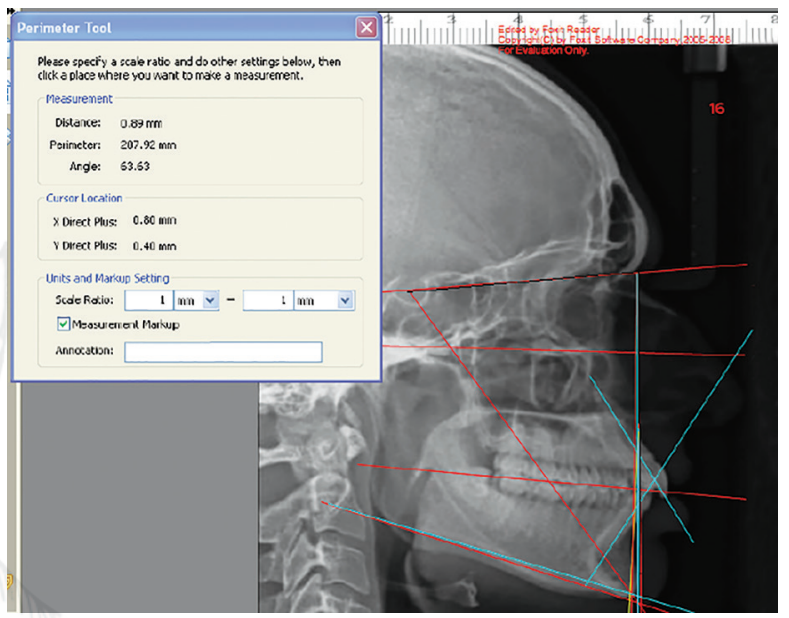

Fig. 2: Cephalometric analysis measurement using Foxit PDF Reader with measurement tools box

the variables and post hoc test followed by Turkey's test was done to check the level of significance.

\section{Result}

The one hundred randomly selected, pre-standardized and precalibrated digital lateral cephalometric radiographs evaluated for the five skeletal and five dental values of Steiner's Analysis, using the measurement tools in the toolbar of Foxit PDF Reader and Nemoceph cephalometric software showed the following.

The mean difference of the skeletal values (SNA, SNB, ANB, mandibular plane angle, and occlusal plane angle) obtained using the two software was comparable clinically ( $\mathrm{min}=0.17$ degree to $\max =1.57$ degree) and showed no significant statistical difference for the variables using One-way ANOVA. A further post hoc test showed the mean difference for the occlusal plane angle to be significantly different from the $p$ value 0.49 , but the values were acceptable clinically (Tables 1 and 2 ) ( ${ }^{*} p \leq 0.5$ significant).

The mean difference of the dental parameters revealed a comparable and clinically acceptable value for the angular measurements, i.e., U1-NA, L1-NB, and Inter incisal angle. Statistical analysis using One-way ANOVA followed by post hoc test showed no statistically significant difference. While the linear measurement 
Table 1: Comparison of skeletal values between groups (one way ANOVA) ( $p \leq 0.5$ significant)

\begin{tabular}{lllll}
\hline Variable & Group & Mean value & \multicolumn{1}{l}{ SD } & p value \\
\hline SNA & Nemoceph & 82.83 & 4.45 & 0.79 \\
& Foxit & 82.16 & 4.97 & \\
SNB & Nemoceph & 78.00 & 5.48 & 0.95 \\
& Foxit & 77.83 & 6.09 & \\
ANB & Nemoceph & 5.15 & 3.15 & 0.69 \\
& Foxit & 5.53 & 3.93 & \\
Mandibular plane angle & Nemoceph & 28.95 & 7.69 & 0.80 \\
& Foxit & 27.73 & 9.03 & \\
Occlusal plane angle & Nemoceph & 15.85 & 6.31 & 0.51 \\
& Foxit & 14.28 & 5.49 & \\
\hline
\end{tabular}

Table 2: Comparison of skeletal values between groups (post hoc test) ( $p \leq 0.5$ significant)

\begin{tabular}{lllll}
\hline & & & Mean \\
Variable & Group & Group & difference & p value \\
\hline SNA & Nemoceph & Foxit & 0.67 & 0.80 \\
SNB & Nemoceph & Foxit & 0.17 & 0.99 \\
ANB & Nemoceph & Foxit & 0.38 & 0.87 \\
Mandibular plane angle & Nemoceph & Foxit & 1.23 & 0.78 \\
Occlusal plane angle & Nemoceph & Foxit & 1.57 & 0.49 \\
\hline
\end{tabular}

Table 3: Comparison of dental values between groups (one-way ANOVA) ( $p \leq 0.5$ significant)

\begin{tabular}{llcrl}
\hline Variable & Group & Mean value & \multicolumn{1}{c}{ SD } & p value \\
\hline U-1 to NA (angle) & Nemoceph & 24.98 & 9.44 & 0.34 \\
& Foxit & 28.23 & 10.79 & \\
U-1 to NA (linear) & Nemoceph & 0.22 & 0.15 & 0.0001 \\
& Foxit & 6.55 & 4.21 & \\
L-1 to NB (angle) & Nemoceph & 29.83 & 6.87 & 0.12 \\
& Foxit & 29.85 & 8.33 & \\
L-1 to NB (linear) & Nemoceph & 0.28 & 0.11 & 0.0001 \\
& Foxit & 7.29 & 2.85 & \\
Inter incisal angle & Nemoceph & 120.29 & 11.93 & 0.73 \\
& Foxit & 118.59 & 10.92 & \\
\hline
\end{tabular}

values, i.e., U1-NA and L1-NB showed a high mean difference of $6.33 \mathrm{~mm}$ and $7.02 \mathrm{~mm}$, respectively between the two software values. Statistical analysis using One-way ANOVA followed by post hoc test showed a statistically significant difference for these parameters with $p$ value 0.0001 (Tables 3 and 4 ) ( ${ }^{*} p \leq 0.5$ significant).

A highly comparable and clinically acceptable mean difference for the angular measurement values of Steiner's analysis, with no statistically significant difference, proves the measurement tools of Foxit PDF Reader to be reliable and cost-effective alternative to commercially available Nemoceph software for cephalometric analysis.

\section{Discussion}

A precise diagnosis and treatment planning is essential to the success of orthodontic treatment. In 1931, orthodontics ushered in the age of radiographic cephalometry. ${ }^{18}$ Since then, the orthodontic domain has achieved a new horizon both in research and clinical science. ${ }^{19,20}$ A number of different cephalometric analyses and norms are available today. ${ }^{21,22}$
Table 4: Comparison of dental values between groups (post hoc test) ( $p \leq 0.5$ significant)

\begin{tabular}{lllll}
\hline Variable & Group & Group & $\begin{array}{l}\text { Mean } \\
\text { difference }\end{array}$ & p value \\
\hline U-1 to NA (angle) & Nemoceph & Foxit & 3.25 & 0.33 \\
U-1 to NA (linear) & Nemoceph & Foxit & 6.33 & 0.0001 \\
L-1 to NB (angle) & Nemoceph & Foxit & 0.02 & 1.00 \\
L-1 to NB (linear) & Nemoceph & Foxit & 7.02 & 0.0001 \\
Inter incisal angle & Nemoceph & Foxit & 1.70 & 0.83 \\
\hline
\end{tabular}

Traditional cephalometric radiography and analysis were done manually using a large inventory and was prone to errors. The technique also is laden with weaknesses. ${ }^{23,24}$

With the rapid evolution of digital radiography landmark location and onscreen tracing has become area of interest for researchers. Computer-aided cephalometric analysis on digitized cephalogram substantially reduces the potential errors, eliminates the production of hard copies, and is time-saving as well. Currently, cephalometric analyses for orthodontic diagnosis, treatment planning, and research are often performed on digital images using computer software. ${ }^{25,26}$ The high cost and availability account limitations of these software programs.

The innovative techniques of Prawat et al. used sonically generated cephalometric values on a digital image analyzer (Digigraph), Shahidi et al. designed software for localization of cephalometric landmarks, and Nouri et al. developed an affordable Iranian cephalometric analysis software program. These techniques have proven to be successful and have overcome the high cost of the commercially available software with success. But again the availability of this software for practicing orthodontists remained dubious, and developing a new software program by an orthodontist is impractical. ${ }^{17,27,28}$

Precision and reproducibility in data is an essential requirement. ${ }^{7}$ Durao et al. reported a lower level of reproducibility in landmarks identification among orthodontists compared to maxillofacial radiologist. ${ }^{29}$

The current study compared the mean difference of the values obtained using the two software, i.e., Nemoceph and Foxit PDF Reader. The pre-standardized and pre-calibrated digital lateral cephalometric radiographs evaluated for the five skeletal and five dental values of Steiner's analysis revealed-the result showed no significant statistical difference in majority. This was in consonance with the study reports of Erkan, et al. (Dolphin Imaging, Vistadent, Nemoceph, and Quick Ceph); Goracci and Ferrari (Nemoceph for Windows, SmileCeph for iPad, and manual), Rusa et al. (Planmeca Romexis, Orthalis, and AxCeph); and Correia, (Radiocef Studio and Dolphin Imaging); who reported a high consistency between the different software evaluated. ${ }^{30-32}$

The mean difference of the observed skeletal values (SNA, SNB, $A N B$, mandibular plane angle, and occlusal plane angle) using the two software in our study ranged from 0.17 degrees to 1.57 degrees, with no statistically significant difference. This was in harmony with the report of Sommer et al. who suggested a difference of below $2^{\circ}$ is clinically acceptable for the mid-face structures. ${ }^{33}$

The dental values in our study showed no statistical significant difference in the majority [L1-NA (angle), L1-NB (angle), and inter incisal angle], except for the linear values of L1-NA and L1-NB. A similar finding for linear values was reported by Celik et al. and Aldrees, using Vistadent software vs Jiffy orthodontic evaluation program and Dolphin Imaging, with lower incisor to different 
reference points, respectively. Study report of Tsorovas and Karsten using five different cephalometric analysis computer programs (Viewbox, OnyxCeph, OrisCeph, Facade, and Winceph) showed better agreement with the advanced features of software for [(L1 to NB $(\mathrm{mm})]$, compared to standard feature. ${ }^{34-36}$

The present study compared the mean values obtained by evaluating 100 digital lateral cephalograms using Nemoceph cephalometric analysis software for windows and the general measurement tools available in the toolbar of Foxit PDF Reader for Steiner's cephalometric analysis. The overall finding of our study showed 80 percent agreement between the two software evaluated with no statistically significant difference. The semiautomatic nature of the Nemoceph Software provides a facility of pop-up guide for landmark identification with an added advantage of consolidated analysis at a single click, but the high cost, specific training, and computer-specific installation and subscription cannot be overruled. The Foxit PDF Reader being available as free download with preexisting linear and angular measurement tools in its toolbar offers an advantage of free use in any computer without the need of internet. Since this is not programmed for specific analysis purposes, therefore can be used with general computer training and without the need of specific instruction. The facility of instant site-specific measurement without the need of complete tracing adds to the advantages of using Foxit PDF Reader for cephalometric analysis and other desired measurements. Therefore, Foxit PDF Reader can be used as an alternative to commercially available Nemoceph software for cephalometric analysis.

\section{Conclusion}

Orthodontics is undergoing a gradual transition and has reached a digital era. The specialty has experienced advancements both in techniques and technology. The present study has shown a comparable and non-significant difference between the data obtained with the two software packages, except for a few exceptions. Therefore, Foxit PDF Reader can be considered as a cost-effective alternative.

\section{LiMITATIONS}

Lateral cephalograms are the most commonly used diagnostic radiograph in clinical orthodontic practice and research. Therefore, the present study sample included only the lateral cephalograms (2D images). The dynamic world of science is moving towards 3D images with a facility of volumetric quantification. The associated high radiation dose and its limited availability pose a limitation to its widespread use. A further study, including 3D images, will be ready to lend a hand.

\section{References}

1. Kommi PB, Venkatesan R, et al. A Cephalometric Assessment of Ideal Nasolabial Angle Range for South Indian Population. J Int Oral Health 2016;8(2):205-207.

2. Soni A, Alladwar N, et al. Evaluation of lateral Cephalometric Norms for Burstone's Analysis in Chhattisgarh by using Nemoceph Software with Lateral Cephalograms Taken in Natural Head Position. Int J Oral Health Dent 2015;1(3):114-119.

3. Turkdonmez CO, Taner L, et al. Craniofacial Evaluation of Class I Turkish Adults: Bimler Analysis. Turk J Orthod 2014;26(4):169-176.

4. Turkdonmez CO, Taner L, et al. Craniofacial Evaluation of Class I Turkish Adults: Bimler Analysis. Turk J Orthod 2014;26(4):169-176.
5. Gribel BF, Gribel MN, et al. Accuracy And Reliability Of Craniometric Measurements On Lateral Cephalometry And 3D Measurements On CBCT Scans. Angle Orthod 2011;81:28-37. DOI: 10.2319/032210-166.1.

6. Naragond A, Kenganal S, etal.Diagnostic Limitations of Cephalometrics in Orthodontics-A Review. J Dent Med Sci 2012;3(1):30-35.

7. Ganna PS, Shetty SK, et al. An Evaluation of the Errors in Cephalometric Measurements on Scanned Lateral Cephalometric Images using Computerized Cephalometric Program and Conventional Tracings. J Indian Orthod Soc 2014;48(4):388-392. DOI: 10.1177/ 0974909820140605 S.

8. Anh TT, Dang TV, et al. Cephalometric Norms For The Vietnamese Population. APOS Trends Orthod 2016;6(4):200-204. DOI: 10.4103/2321-1407.186435.

9. Purmal K, Alam MK, et al. Cephalometric Norms of Malaysian Adult Chinese. Int Med J 2013;20(1):87-91.

10. Da Silva JMG, De Melo Castilho JC, et al. Comparative Study Between Conventional And Digital Radiography In Cephalometric Analysis. J Health Sci Inst 2011;29(1):19-22.

11. Gupta G, Tripathi AA, et al. Cephalometric VTO: A Blueprint. Heal Talk 2013;05(3):47-50.

12. Rodrigues $C D$, Da Silveira MMF, et al. Evaluation Of Indirect Methods Of Digitization Of Cephalometric Radiographs In Comparison With The direct Digital Method. Dental Press J Orthod 2010;15(4):124-132. DOI: 10.1590/S2176-94512010000400017.

13. Oshagh M, Shahidi S, et al. Effects Of Image Enhancement On Reliability Of Landmark Identification In Digital Cephalometry. Indian J Dent Res 2013;24(1):98-103.

14. Segura FJE, Valverde AS, et al. Comparative Study Between Digital And Manual Cephalometry With Digital Radiographs. Rev Mex Ortodoncia 2014;2(2):93-96.

15. Sayinsu K, Isik F, et al. An evaluation of the errors in cephalometric measurements on scanned cephalometric images and conventional tracings. Eur J Orthod 2007;29:105-108. DOI: 10.1093/ejo/ cjl065.

16. Grybauskas S, Balciuniene I, et al. Validity and Reproducibility of Cephalometric Measurements Obtained from Digital Photographs of Analogue Headfilms. Stomatologija Baltic Dental and Maxillofacial Journal 2007;9(4):114-120.

17. Nouri M, Hamidiaval S, et al. Efficacy of a Newly Designed Cephalometric Analysis Software for McNamara Analysis in Comparison with Dolphin Software. J Dent 2015;12(1):60-69.

18. Paixao MB, Sobral MC, et al. Comparative Study Between Manual And Digital Cephalometric Tracing Using Dolphin Imaging Software With Lateral Radiographs. Dental Press J Orthod 2010;15(6):123-130. DOI: 10.1590/S2176-94512010000600016.

19. Erkan M, Gurel HG, et al. Reliability of Four Different Computerized Cephalometric Analysis Programs. Eur J Orthod 2012;34(3):318-321. DOI: 10.1093/ejo/cjr008.

20. Kumar V, Sundareswaran S. Cephalo metric assessment of sagittal dysplasia: a review of twenty one methods. J Indian Orthod Soc 2015;48(1):33-41.

21. Cutoviu T, Joviu N, et al. Cephalometric analysis of the middle part of the face in patients with mandibular prognathism. Vojnosanit Pregl 2014;71(11):1026-1033. DOI: 10.2298/VSP1411026C.

22. Purmal K, Alam MK, et al. Cephalometric Norms of Malaysian Adult Chinese. Int Med J 2013;20(1):87-91.

23. McNamara JA. A Method of Cephalometric Evaluation. Am J Orthod 1984;86(6):449-469. DOI: 10.1016/S0002-9416(84)90352-X.

24. Naoumova J, Lindman R. A Comparison of Manual Traced Images and Corresponding Scanned Radiographs Digitally Traced. Eur J Orthod 2009;31(3):247-253. DOI: 10.1093/ejo/cjn110.

25. Kumar D, Solanki R, et al. Cephalometric Landmark Identification by Conventional and Digital Direct Radiography in Skeletal Class II Individuals. Int J Res Educ Sci Methods 2015;3(12):6-10.

26. Oshagh M, Shahidi S, et al. Effects Of Image Enhancement On Reliability Of Landmark Identification In Digital Cephalometry. Indian J Dent Res 2013;24(1):98-103. DOI: 10.4103/0970-9290.114958. 
27. Prawat JS, Nieberg L, et al. A Comparision Between Radiographically And Sonically Produced Cephalometric Values. Angle Orthod 1995;65(4):271-276.

28. Shahidi S, Oshagh M, et al. Accuracy of Computerized Automatic Identification of Cephalometric Landmarks by a Designed Software. Dentomaxillofac Radiol 2013;42:1-8. DOI: 10.1259/dmfr.20110187.

29. Durao APR, Morosolli A, et al. Cephalometric landmark variability among orthodontists and dentomaxillofacial radiologists: a comparative study. Imaging Sci Dent 2015;45:213-220. DOI: 10.5624/ isd.2015.45.4.213.

30. Goracci C, Ferrari M. Reproducibility of measurements in Tabletassisted, PC-Aided, and Manual Cephalometric Analysis. Angle Orthod 2014;84:437-442. DOI: 10.2319/061513-451.1.

31. Rusu OL, Petcu AE, et al. Reliability and Accuracy of Three Different Computerized Cephalometric Analysis Software. Rev Med Chir Soc Med Nat lasi 2015;119(1):248-256.
32. Correia TRGS, Sena LMFD, et al. Cephalometric Analysis: Concordance Between Software. Rev Gaucha Odontol (Porto Alegre) 2017;65(4): 321-325. DOI: 10.1590/1981-863720170002000063275.

33. Celik E, Polat-Ozsoy O, et al. Comparison of Cephalometric Measurements with Digital Versus Conventional Cephalometric Analysis. Eur J Orthod 2009;31:241-246. DOI: 10.1093/ejo/cjn105.

34. Sommer T, Ciesielski R, et al. Precision of Cephalometric Analysis via Fully and Semiautomatic Evaluation of Digital Lateral Cephalographs. Dentomaxillofac Radiol 2009;38:401-406. DOI: 10.1259/dmfr/85543699.

35. Tsorovas G, Karsten ALA. A Comparison of Hand-Tracing and Cephalometric Analysis Computer Programs With and Without Advanced Features - Accuracy and Time Demands. Eur J Orthod 2010;32:721-728. DOI: 10.1093/ejo/cjq009.

36. Aldrees AM. Evaluation of Incisors Inclination in Five Cephalometric Analysis Methods. Pak Oral Dent J 2010;30(2):1-8. 